\title{
Defining Neuromarketing: Practices and Professional Challenges
}

\author{
Carl Erik Fisher, MD, Lisa Chin, EdD, JD, MA, MPH, and Robert Klitzman, MD \\ Department of Psychiatry, Columbia University; New York State Psychiatric Institute, New York, \\ NY
}

\begin{abstract}
Neuromarketing has recently generated controversies concerning the involvement of medical professionals, and many key questions remain —ones that have potentially important implications for the field of psychiatry. Conflicting definitions of neuromarketing have been proposed, and little is known about the actual practices of companies, physicians, and scientists involved in its practice. This article reviews the history of neuromarketing and uses an exploratory survey of neuromarketing Web sites to illustrate ethical issues raised by this new field. Neuromarketing, as currently practiced, is heterogeneous, as companies are offering a variety of technologies. Many companies employ academicians and professionals, but few list their clients or fees. Media coverage of neuromarketing appears disproportionately high compared to the paucity of peerreviewed reports in the field. Companies may be making premature claims about the power of neuroscience to predict consumer behavior. Overall, neuromarketing has important implications for academic-industrial partnerships, the responsible conduct of research, and the public understanding of the brain. We explore these themes to uncover issues relevant to professional ethics, research, and policy. Of particular relevance to psychiatry, neuromarketing may be seen as an extension of the search for quantification and certainty in previously indefinite aspects of human behavior.
\end{abstract}

\section{Keywords}

bioethics; conflicts of interest; ethics; fMRI; neuroethics; neuromarketing; professionalism

\begin{abstract}
Psychiatry is increasingly embracing functional magnetic resonance imaging (fMRI) and other neurotechnologies, which carry the promise of revealing the underpinnings of emotions and social interactions. Similarly, various domains have acquired the prefix neuroas brain science increasingly informs our daily lives, social practices, and intellectual discourses. This collection of new fields-for example, neuroaesthetics, neurotheology, and neuroeducation - has been labeled neuroculture, and the brain-based explanations arising from it are progressively influencing public notions of personal identity, responsibility, and causation. ${ }^{1}$ Neuromarketing, which can be tentatively defined as marketing designed on the basis of neuroscience research, is one manifestation of this new neuroculture. The field offers insights into the development of brain-based narratives and into the potential problems that they might pose for medical ethics and the public understanding of science.
\end{abstract}

(C) 2010 President and Fellows of Harvard College

Correspondence: Carl Erik Fisher, MD, Department of Psychiatry, New York State Psychiatric Institute, 1051 Riverside Dr., Box 103, New York, NY 10032.cf2141@columbia.edu.

Declaration of interest: The authors report no conflicts of interest. The authors alone are responsible for the content and writing of the article. 
Neuromarketing has attracted increasing attention, but critical aspects of it remain underexplored, including what exactly it is or includes, and how it is used in practice. The field has already generated controversy. For example, the popular press has reported on the perceived dangers of neuromarketing, including concerns that advertisers might find a "buy button" or "magic spot" in the brain,2,3 editorials in the scientific literature have argued that these worries are most likely premature since the current state of imaging technology does not allow for accurate, deterministic predictions of human decision making; ${ }^{4,5}$ and still others have expressed concerns that neuromarketing might one day threaten individual autonomy if this technology were able to effectively manipulate consumer behavior. ${ }^{6}$ Indeed, the authors of one recent review are optimistic about the potential of this technology, asserting that neuromarketing will "soon be able to reveal hidden information about consumer preferences"- though they recognize that this technology is unlikely to be more cost-effective than traditional marketing. ${ }^{7}$

Universities and medical professionals have been criticized for forming partnerships with neuromarketing companies. ${ }^{8}$ For example, consumer groups claimed that Emory University violated the Belmont Report's principle of beneficence when it partnered with a neuromarketing company; the groups asserted that this research promotes "socially harmful" results such as increasing sales of unhealthy food or facilitating political propaganda. ${ }^{8}$

Yet, surprisingly, there have been few descriptions of neuromarketing as it currently exists, and many key aspects of such companies are unknown: to what extent these technologies are actually being used in the private sector; whether and how they are associated with academicians; and what claims are being made. Indeed, there is little consensus over what should be considered neuromarketing at all.

This new development in neuroscience has important implications for the public understanding of science. Some have argued that the public understanding of brain imaging lacks sufficient skepticism. ${ }^{9}$ The public may not always realize that the colorful results in a functional brain scan appear as such only after extensive image processing and statistical analyses, and in the context of a specific experimental paradigm. ${ }^{10}$ Indeed, members of the public find descriptions of neuroscience findings more persuasive when descriptions of research are accompanied by brain images-even though these images have no actual impact on the objective validity of those findings. ${ }^{11}$

\section{WHAT IS NEUROMARKETING?}

The earliest reported use of the word neuromarketing appears to be in a June 2002 press release by an Atlanta advertising firm, BrightHouse, announcing the creation of a business division using fMRI for marketing research. ${ }^{12}$ This firm quickly attracted criticism for potential conflicts of interest involving Emory University; the new business division of BrightHouse was established by Emory faculty, including at least one professor in psychiatry, and the imaging studies used Emory's facilities. ${ }^{8}$ The anti-advertising civic group Commercial Alert advanced some of the most vocal criticisms of this work-for example, the spread of "marketing-related diseases" resulting from the promotion of junk food companies-and they soon asked the federal Office for Human Research Protections and the U.S. Senate to investigate BrightHouse's research. ${ }^{13}$ The Web site for BrightHouse Neurostrategies, as it was called, was quickly taken down, and the new enterprise faded from public attention.

Long before this type of work acquired its neuro-prefix, however, and long before Emory University and BrightHouse announced their partnership, corporations have sponsored neurophysiologic research into marketing topics-for example, by studying consumer reactions to television programming with electroencephalography (EEG). ${ }^{14,15}$ Of note, four 
years before the term neuromarketing was coined, Professors Gerald Zaltman and Stephen Kosslyn of Harvard University ${ }^{16}$ filed a patent for "Neuroimaging as a marketing tool"; however, Zaltman quickly shifted his focus to the "Zaltman Metaphor Elicitation Technique," a structured interview that does not employ imaging technology, and Kosslyn appears not to have been involved in neuromarketing until 2008, when he joined the advisory board of a company called NeuroFocus. ${ }^{17,18}$

More recently, researchers have proposed conflicting definitions of neuromarketing, preferring to see it as essentially a scientific field rather than as a business. Specifically, Lee and colleagues ${ }^{19}$ have defined neuromarketing as academic scholarship: "a valid field of study" and not simply "the application of neuroimaging techniques to sell products." Some companies that describe their activities as neuromarketing have not published their results in peer-reviewed journals, however, and their efforts seem contained largely within the private sector. Thus, in contrast to Lee and colleagues, Hubert and Kenning ${ }^{20}$ see neuromarketing as a business activity rather than an academic field focused on scholarship. They propose that the broader field of neuroscientific consumer research (what Lee and colleagues refer to as neuromarketing) should be labeled "consumer neuroscience," and they define neuromarketing more narrowly as "the application of these findings within the scope of managerial practice."

A useful comparison can be made to neuroeconomics, an academic discipline that studies various aspects of economic decision making. ${ }^{21}$ This field has also attracted attention recently and often uses imaging technology, but it is more clearly an academic discipline. Recent commentators echo the above distinction between scholarship and application, asserting that neuroeconomics should be considered apart from specific investigations for marketing purposes. ${ }^{2}$ Neuroeconomics has undergone extensive theoretical development as a field, ${ }^{21-24}$ and it has already produced a wealth of evidence on decision making in realworld contexts. Neuroeconomics researchers often use commonly recognized objects like consumer products to study general concepts like sensory processing, choice, and the evaluation of losses and rewards, but these studies are not done for a particular company or marketing application. For example, McClure and colleagues ${ }^{25}$ examined subjects' responses to Coke and Pepsi using fMRI; this model was chosen to understand sensory perception of common cultural symbols, not to aid the Coca-Cola Company or PepsiCo in their marketing design. More broadly, much neuroscience and psychology research is potentially useful for understanding choice and preference, but is not neuroeconomics (or neuromarketing) per se. The neuroeconomics community now comprises over one dozen university-based research centers, one scientific society, and a considerable literature that includes numerous textbooks.

In contrast, the academic foundations of neuromarketing as a field are difficult to identify. It is unclear at present whether neuromarketing qualifies as an academic field, and if it does, what distinguishes it from neuroeconomics. We have found only a handful of scholarly reports of the results of industry-sponsored neuromarketing. In 2002, scientists from the University of Ulm in Germany, supported by Daimler Chrysler, published a report on the visual perception of automobiles, ${ }^{26}$ and scientists at UCLA received partial funding from the political consultancy FKF Research to analyze the neural reactions of registered Republicans and Democrats to faces of presidential candidates. ${ }^{27}$ Anecdotally, a few companies have also conducted neuromarketing studies but have not published their work in peer-reviewed journals. For example, researchers at Caltech's Social Cognitive Neuroscience Laboratory have reportedly partnered with Lieberman Research to help Hollywood studios select movie trailers. ${ }^{3}$ 
But beyond these few cases, it is not clear how widespread neuromarketing is or even exactly what it is. Thus, several critical questions remain: Does neuromarketing involve more than this handful of companies? How are these companies presenting themselves and neuromarketing itself? To what extent are medical professionals and academicians involved in their work? What claims are they making? What are the ethical obligations of medical professionals, including psychiatrists, with regard to this new practice? To examine these themes, we performed an exploratory study to capture a sense of the range, variety, and frequency of key characteristics of neuromarketing companies. Since an ever burgeoning amount of medical information is being offered through the Internet, ${ }^{28-31}$ we decided to examine these issues through neuromarketing Web sites.

\section{NEUROMARKETING WEB SITES}

To probe the similarities, differences, and patterns that might appear among neuromarketing companies, we searched Google for "neuromarketing." We examined the maximum number of available hits-1,000 in this case - and identified 16 companies offering neuromarketing services. We included all marketing sites that described any neuro-science methods but excluded Web logs (blogs), media sites, and other noncommercial hits that did not offer such services. Then, using the methodology we have described previously to study how the Web sites of in vitro fertilization clinics present the risks and benefits of preimplantation genetic diagnosis, ${ }^{32}$ we developed a coding strategy to qualitatively describe these neuromarketing sites. In brief, we each independently read the 16 Web sites, developed categories to code, and worked together to reconcile the three independently developed coding schemes into a single scheme. With that scheme in place, we reviewed all of the Web sites and assigned codes together. The results are presented in the text box on the next page.

Early commentators assumed the term neuromarketing indicated the use of brain imaging such as fMRI, ${ }^{4}$ but many companies seem not to use imaging but rely, instead, on a variety of technologies (or on no technology at all). As shown in the text box, of the 16 companies identified, only 5 offered fMRI; 9 offered EEG services; and 12 offered some other neuroscience-related technology, including: magnetoencephalography, "psychophysics," software services, eye tracking, galvanic skin response, electrocardiography, electromyography, and analysis of pupil dilation, blush, blinking, heartbeat, or breathing. Of note, one company did not offer any technology; instead, it offered only focus groups and other simple marketing strategies, but described these methods using neuroscience terms.

Only four companies listed their clients, and only one listed costs. This relatively limited transparency is relevant to consumer groups' criticisms of Emory University. Those groups alleged that companies could be secretly damaging public health by promoting unhealthy products like junk food or cigarettes, or that they could even threaten individual liberty by designing more effective political propaganda. ${ }^{8}$ While this line of attack may seem alarmist to some, it is comparable to the criticisms levied against academic medical centers during debates about the divestment of tobacco stock-which were made on the basis of the mission of academic medical centers to protect the public health. ${ }^{33}$

In terms of the science itself, 13 companies described their methodology, but these descriptions were often insufficient to determine what was being done. For example, one stated that it could "measure almost any form of stimulus material in many different types of environment" via "[t]echniques" involving "[n]eurological responses via EEG eg [sic] the nature and intensity of different mind-state shifts, levels of attention and emotions."* In

\footnotetext{
*The concern here is not about specific companies but about the broader phenomenon of neuromarketing. Although we have therefore not included the sources of the quotations from neuromarketing Web sites, we do have the original sources on file.
} 
most cases, the companies alluded to techniques or simply listed technologies without describing the actual experimental design. Furthermore, little evidence was provided for their claims. Eleven Web sites did not reference any peer-reviewed articles, either in support of their methods or as reports of their previous work. Six included caveats to their technology, and only one company provided citations for its specific claims.

The examples that we found illustrate the confusion over the precise disciplinary definition of neuromarketing: whether it is essentially an academic field or a marketing application. Five of these companies do employ academicians; five sites reference the academic literature; and one had a university affiliation. The involvement of professionals is comparatively larger, as nine sites had holders of advanced science degrees on staff (more PhDs than MDs).

Seven sites displayed some graphic depiction of the brain on their home pages, and nine had a picture of the brain or of other "data." Nine also had links to media coverage.

With regard to the claims themselves, the majority (10 of 16) of the neuromarketing companies promised the "truth" or what customers "really" think; for example: "we measure what consumers really think and feel, rather than simply what they state," or we "unlock what your customer really thinks." Ten also invoked the workings of the sub- or unconscious mind in relation to their methods (e.g., "These measurements ... will reveal mental activity operating below the level of conscious awareness."). Half explicitly claimed that their methods were an improvement over past technologies, though only one company claimed that it could predict future behavior. In light of the current state of imaging technology, these claims appear questionable at best.

As shown in the text box on the next page, we saw a variety of claims suggesting reductionism, which the Oxford English Dictionary defines as the practice of describing or explaining a complex phenomenon in terms of relatively simple or fundamental concepts. ${ }^{34}$ In this case, reductionism was apparent in statements such as "types and levels of emotions" or "what part of the brain is telling" consumers to make decisions. Other examples were less striking but still seemed to suggest a simplistic explanation for complex brain processes (e.g., "quantify and localise brain activity in areas involved in emotion, attention, memory and decision-making") We did not develop an additional code for this process of oversimplification; it was too difficult and uncertain to specify exactly when an interpretation of neuroscientific findings becomes reductionistic. However, we thought it important to bring these examples to light, as they seem to capitalize on the public fascination with neuroscience. Racine and colleagues ${ }^{35}$ have described a concept they term neuro-essentialism: the immediate, uninquisitive equation of identity and agency to the brain and its substructures. Similarly, Vidal ${ }^{36}$ has proposed the concept of brainhood: the condition of "being rather than having a brain," in which humans are "cerebral subjects" whose selfhood is determined by their brains alone. Indeed, these examples seem to go beyond simply overvaluing technology to suggest that all human behavior and thought can be reduced to regional brain activity.

Finally, none of the Web sites mentioned issues of privacy or confidentiality (e.g., who else, if anyone, might have access to data that are collected) and what, if anything, might be done with incidental findings (e.g., evidence of pathology).

\section{DISCUSSION}

This brief study raises several broader issues relevant to the public understanding of science and academic professionalism. 


\section{Public Understanding of Science}

It is worrisome that neuromarketing companies appear to be providing links to media rather than to scientific literature, as media coverage could be used in the absence of peer-reviewed evidence to prematurely legitimize the use of these technologies. The media has an important role in communicating scientific discoveries, but multidirectional communication between neuroscientists and the lay public is more desirable than relying on the media alone to disseminate scientific results; media reports alone may not sufficiently capture essential limitations of specific studies. ${ }^{37}$

Many of the Web sites that we found included some graphical representation of brain function, such as a picture of a brain, cartoon data, or other suggestive graphics. This marketing approach is probably effective; as mentioned above, when descriptions of research findings are accompanied by graphical representations, laypersons consider those results more believable. ${ }^{11}$ The use of such graphics may be problematic, however, as their widespread use may obscure certain scientific and technological limitations that have a general tendency to be ignored when such methods are popularized. Among other things, since these vivid graphics are produced only through intensive statistical and image processing, the results can be manipulated to highlight or underplay differences among brain regions. Further problems derive from the physical nature of the signal on which these methods rely. All neurotechnologies measure surrogate signals for neural activity (such as the blood oxygen level-dependent, or BOLD, response of fMRI), and these signals are constrained by the physical and biological limitations of the technology in question and the brain itself. This dependence upon surrogate signals, rather than direct measures, is typically ignored in popular depictions of neuroscience, such as when technologies are described as direct windows into the working of the brain (e.g., "we can literally 'map' the human mind as it reacts to stimuli").

It appears that few neuromarketing companies have published their results. These findings could be scientifically useful, and companies would be performing a valuable public service if they published them in the academic literature. Such dissemination is unlikely, however, because of the proprietary nature of such findings and their potential strategic usefulness, and it is also unlikely that neuromarketing companies (like any other for-profit businesses) can be compelled to release those results. Such an intervention might be warranted if neuromarketing were actually able to manipulate consumer behavior and if the targets of that marketing effort could not detect that they were being manipulated. This scenario, which is described as stealth neuromarketing in one analysis, ${ }^{6}$ is not possible using current technology. If and when it does become possible, however, it would surely represent a significant threat to consumer autonomy-so much so that it would fundamentally alter our understanding of autonomy and free will. But for now, neuromarketing companies bear no special duty to transparency.

\section{Professional and Academic Conduct}

Psychiatry has often served as a crucible for testing new ideas about the brain and mind, and the example of neuromarketing may hold lessons for our field. The current value granted to neuroimaging could be said to descend directly from the late-nineteenth-century concept of "instruments of precision." 38 From thermometers and blood pressure cuffs to EEG and fMRI machines, medical researchers have long striven to quantify previously subjective observations. Neuromarketing, as one of the earliest manifestations of commercialized neuroscience in the post-imaging era, may well be a harbinger of developments within psychiatry - for example, a rush toward diagnostic certainty through imaging. Indeed, one for-profit venture is already marketing the use of brain imaging for psychiatric diagnosis. ${ }^{39}$ Psychiatry as a field should closely consider the limitations of such measures. At a time 
when the development of the new Diagnostic and Statistical Manual is attracting vigorous public commentary, and when the validity of psychiatric diagnosis is publicly debated, the claim that imaging technology is a unique route to diagnostic certainty could be a premature way to seek to legitimize complex disease concepts; if these new methods or the concepts they support are not consistently found to be valid and reliable, "neuronosology" could undercut public trust in psychiatric research.

Several topics in medical professionalism suggest further concerns. There exists a sizeable literature on conflicts of interest in medicine, and in view of the potential for such conflicts to encourage reporting bias ${ }^{40}$ and data withholding, ${ }^{41}$ detailed proposals for academic medical centers have been advanced. Regarding communications and the public understanding of science, however-unlike research per se-there is little specific guidance about professional involvement with entrepreneurial ventures such as neuromarketing. The Charter on Medical Professionalism identifies one aspect of professionalism as "providing expert advice to society on matters of health," 42 and previous writers have highlighted the need for physicians to counteract declining trust in the medical profession by doing work that "contributes to the public value for which the profession stands." ${ }^{3}$ Society expects the medical profession to be beneficent: honest, accountable, transparent, and a source of objective advice and information. ${ }^{44}$ Some have urged physicians to be more engaged in the public arena, but these discussions often refer primarily to advocacy and activism, not public communications about science. ${ }^{45}$

Since neuromarketing has socially and ethically relevant implications-for example, regarding self, agency, and free will-it is important to consider closely the participation of medical professionals in neuromarketing companies. ${ }^{46}$ Considering that the field of neuromarketing is still emerging, it is premature to recommend prohibiting professionals from becoming involved at all. That said, academic medical centers might well consider formulating policies to address concerns about neuromarketing. Survey data have revealed that institutional policies around conflicts of interest vary significantly ${ }^{47}$ and that most such policies lack specificity. ${ }^{48}$ Academic medical centers could take the lead in promoting transparency regarding neuromarketing and similar enterprises by requiring their faculty to publish consulting agreements, advisory positions, and other entrepreneurial relationships on a publically available source such as the institution's Web site. This suggestion mirrors existing policy proposals regarding ties to pharmaceutical companies-policies that, in an attempt to safeguard against bias in reporting research results, require the posting of information about such ties. ${ }^{49}$

More broadly, all academicians have a duty to the public trust: they need to communicate clearly about science and cannot rely on the popular press to fulfill that responsibility with the same clarity and accuracy.$^{50}$ Gibbons ${ }^{51}$ has proposed that the production of scientific knowledge should be seen by society to be "both transparent and participative." It is troubling that in our example of neuromarketing, companies with academicians on staff have made questionable claims without evidence-based citations. Indeed, promising to deliver a deterministic way of understanding and ultimately manipulating consumer behavior is premature, and over time such unrealistic claims could be seen as a violation of an implicit social contract—and as harming public respect for science and jeopardizing public support of research in general. ${ }^{52}$

Individual neuromarketing companies and the academicians employed by them should recognize the potential benefit to be gained by instituting better practices on their own - for instance, to avoid unfounded claims and to adhere more closely to accepted standards of scientific evidence. In response to the perceived excesses of neuromarketing, some observers have suggested that legislation may be needed to regulate the commercial use of 
imaging technology. ${ }^{5}$ Self-regulation by industry and by individual academicians might help to forestall such restrictions while simultaneously improving transparency and research quality. Similarly, while these companies are not under the purview of health privacy laws, as they are not health care providers, they should have measures in place both to protect the confidentiality of the data that they record and to enable the portability of images, records, and other information that might prove to be useful for their subjects. Considering that neuromarketing studies might disclose important radiologic findings, companies should have an explicit protocol in place for reporting and referral, as recommended by Murphy and colleagues. ${ }^{6}$

\section{CONCLUSIONS}

The issues raised by neuromarketing highlight important professional, ethical, and scientific concerns. This new field exemplifies the complicated issue of professional ethics as applied to academic-industrial relationships. Furthermore, as a new application of neuroscience methods, neuromarketing raises important considerations for the responsible conduct of research and the public understanding of neuroscience.

More research is needed in order to better understand neuromarketing, neuromarketing companies, and their practices and claims. Our exploration of these companies used only publicly presented information. Further investigations could directly assess the actual roles of professionals and academics in these companies. For example: whether they are in a position to oversee the collection, interpretation, or dissemination of research findings; how the roles of academicians are defined; and whether they are paid. Several questions remain: Who is using neuromarketing, and for what specifically? What advice and data do they receive as part of these services? And do they perceive any return on investment?

It would be interesting to investigate the quality of neuromarketing research directly since the private sponsorship of biomedical research has been found to be associated with proindustry conclusions. ${ }^{39}$ As neuromarketing grows in scale and enters more fully into society, as well as into various media and economic marketplaces, the concerns expressed here about the industry's claims and about the roles of professionals in promoting scientific legitimacy will become increasingly important.

Psychiatrists in academics and clinical practice alike should be alert to the implications of new neurotechnologies, including neuromarketing, as these applications carry important consequences for both the public trust in academic medicine and the public's evolving comprehension of mind/brain interrelationships.

\section{Acknowledgments}

Supported, in part, by a Doris Duke Charitable Foundation Clinical Research Fellowship (CEF); National Institute of Mental Health training grant no. T32 MH19139 (LC); and U.S. Department of Health and Human Services Office of Research Integrity grant no. 1R01HG004214-01 (RK).

Thanks to Paul Appelbaum for helpful comments on an earlier version of this paper.

\section{REFERENCES}

1. Frazzetto G, Anker S. Neuroculture. Nat Rev Neurosci. 2009; 10:815-21. [PubMed: 19841632]

2. Blakeslee S. If you have a 'buy button' in your brain, what pushes it? N Y Times. Oct 19.2004

3. Thompson C. There's a sucker born in every medial prefrontal cortex. N Y Times Mag. Oct 26.2003

4. Brain scam? Nat Neurosci. 2004; 7:683. [PubMed: 15220922]

5. Neuromarketing: beyond branding. Lancet Neurol. 2004; 3:71. [PubMed: 14746993] 
6. Murphy ER, Illes J, Reiner PB. Neuroethics of neuromarketing. J Consum Behav. 2008; 7:293-302.

7. Ariely D, Berns GS. Neuromarketing: the hope and hype of neuroimaging in business. Nat Rev Neurosci. 2010; 11:284-92. [PubMed: 20197790]

8. Ruskin, G. Commercial alert asks feds to investigate neuromarketing research at Emory University. December 17. 2003 http://www.commercialalert.org/news/news-releases/2003/ 12/commercial-alert-asks-feds-toinvestigate-neuromarketing-research-at-emory-university

9. Farah MJ. Neuroethics: the practical and the philosophical. Trends Cogn Sci. 2005; 9:34-40. [PubMed: 15639439]

10. Canli T, Amin Z. Neuroimaging of emotion and personality: scientific evidence and ethical considerations. Brain Cogn. 2002; 50:414-31. [PubMed: 12480487]

11. McCabe DP, Castel AD. Seeing is believing: the effect of brain images on judgments of scientific reasoning. Cognition. 2008; 107:343-52. [PubMed: 17803985]

12. Brighthouse Institute for Thought Sciences launches first "neuromarketing" research company. June 22. 2002 http://www.prweb.com/releases/2002/6/prweb40936.php

13. Canli, T. When genes and brains unite: ethical implications of genomic neuroimaging. In: Illes, J., editor. Neuroethics. Oxford University Press; Oxford: 2006.

14. Krugman HE. Brain wave measures of media involvement. J Advertising Res. 1971; 11:3-10.

15. Rothschild M, Hyun YJ. Predicting memory for components of TV commercials from EEG. J Consum Res. 1990; 16:472-8.

16. Zaltman, G.; Kosslyn, SM. Neuroimaging as a marketing tool. U.S. Patent. 6,099,319. August 8. 2000

17. Lewis D, Bridger D. Market researchers make increasing use of brain imaging. Adv Clin Neurosci Rehabil. 2005; 5:3.

18. Neurofocus appoints Stephen Kosslyn to its Advisory Board. September 17. 2009 http://www.neurofocus.com/news/stephen.htm

19. Lee N, Broderick AJ, Chamberlain L. What is `neuromarketing'? A discussion and agenda for future research. Int J Psychophysiol. 2007; 63:199-204. [PubMed: 16769143]

20. Hubert M, Kenning P. A current overview of consumer neuro-science. J Consum Behav. 2008; 7:272-92.

21. Glimcher P. Neuroeconomics: the consilience of brain and decision. Science. 2004; 306:447-52. [PubMed: 15486291]

22. Lowenstein G. Neuroeconomics. Annu Rev Psychol. 2008; 59:647-72. [PubMed: 17883335]

23. Sanfey A, Loewenstein G, McClure S, Cohen JD. Neuroeconomics: cross-currents in research on decision-making. Trends Cogn Sci. 2006; 10:108-16. [PubMed: 16469524]

24. Zak PJ. Neuroeconomics. Philos Trans R Soc Lond B Biol Sci. 2004; 359:1737-48. [PubMed: 15590614]

25. McClure SM, Li J, Tomlin D, Cypert KS, Montague LM, Montague PR. Neural correlates of behavioral reference for culturally familiar drinks. Neuron. 2004; 44:379-87. [PubMed: 15473974]

26. Erk S, Spitzer M, Wunderlich AP, Galley L, Walter H. Cultural objects modulate reward circuitry. Neuroreport. 2002; 13:2499-503. [PubMed: 12499856]

27. Kaplan JT, Freedman J, Iacoboni M. Us versus them: political attitudes and party affiliation influence neural response to faces of presidential candidates. Neuropsychologia. 2007; 45:55-64. [PubMed: 16764897]

28. Hajjar I, Gable SA, Jenkinson VP, Kane LT, Riley RA. Quality of Internet geriatric health information: the GeriatricWeb project. J Am Geriatr Soc. 2005; 53:885-90. [PubMed: 15877570]

29. Cheung BK, Morze CJ, Jones MA, Venkatesh B. Information on the Internet about head injury pertaining to intensive care: less quantity and more quality is needed. Crit Care Resusc. 2006; 8:100-6. [PubMed: 16749874]

30. Hargrave DR, Hargrave UA, Bouffet E. Quality of health information on the Internet in pediatric neuro-oncology. Neuro Oncol. 2006; 8:175-82. [PubMed: 16533758] 
31. Bernstam EV, Walji MF, Sagaram S, Sagaram D, Johnson CW, Meric-Bernstam F. Commonly cited website quality criteria are not effective at identifying inaccurate online information about breast cancer. Cancer. 2008; 111:1206-13. [PubMed: 18266210]

32. Klitzman R, Zolovska B, Folberth W, Sauer MV, Chung W, Appelbaum P. Preimplantation genetic diagnosis on in vitro fertilization clinic websites: presentations of risks, benefits and other information. Fertil Steril. 2009; 92:1276-83. Epub 2008 Sep 30. [PubMed: 18829009]

33. Wander N, Malone RE. Selling off or selling out? Medical schools and ethical leadership in tobacco stock divestment. Acad Med. 2004; 79:1017-26. [PubMed: 15504765]

34. Oxford English dictionary. Oxford University Press; New York: 2009. Reductionism.

35. Racine E, Bar-Ilan O, Illes J. fMRI in the public eye. Nat Rev Neurosci. 2005; 6:159-64. [PubMed: 15685221]

36. Vidal F. Brainhood, anthropological figure of modernity. Hist Human Sci. 2009; 22:5-36.

37. Rose SP. How to (or not to) communicate science. Biochem Soc Trans. 2003; 31:307-12. [PubMed: 12653626]

38. Matthews, JR. Quantification and the quest for medical certainty. Princeton University Press; Princeton, NJ: 1995.

39. Amen Clinics. http://www.amenclinics.com

40. Bekelman JE, Li Y, Gross CP. Scope and impact of financial conflicts of interest in biomedical research. JAMA. 2003; 289:454-65. [PubMed: 12533125]

41. Campbell EG, Clarridge BR, Gokhale M, et al. Data withholding in academic genetics: evidence from a national survey. JAMA. 2002; 287:473-80. [PubMed: 11798369]

42. American Board of Internal Medicine; ACP-ASIM Foundation. American College of PhysiciansAmerican Society of Internal Medicine; European Federation of Internal Medicine. Medical professionalism in the new millennium: a physician charter. Ann Intern Med. 2002; 136:243-6. [PubMed: 11827500]

43. Sullivan, W. Work and integrity: the crisis and promise of professionalism in North America. 2nd ed.. Jossey-Bass; San Francisco: 2005.

44. Cruess RL, Cruess SR. Expectations and obligations: professionalism and medicine's social contract with society. Perspect Biol Med. 2008; 51:579-98. [PubMed: 18997360]

45. Gruen RL, Pearson SD, Brennan TA. Physician-citizens-public roles and professional obligations. JAMA. 2004; 291:94-8. [PubMed: 14709581]

46. Roskies A. Neuroethics for the new millenium. Neuron. 2002; 35:21-3. [PubMed: 12123605]

47. McCrary SV, Anderson CB, Jakovljevic J, et al. A national survey of policies on disclosure of conflicts of interest in biomedical research. N Engl J Med. 2000; 343:1621-6. [PubMed: 11096171]

48. Cho MK, Shohara R, Schissel A, Rennie D. Policies on faculty conflicts of interest at US universities. JAMA. 2000; 284:2203-8. [PubMed: 11056591]

49. Brennan TA, Rothman DJ, Blank L, et al. Health industry practices that create conflicts of interest: a policy proposal for academic medical centers. JAMA. 2006; 295:429-33. [PubMed: 16434633]

50. Kulynych J. Legal and ethical issues in neuroimaging research: human subjects protection, medical privacy, and the public communication of research results. Brain Cogn. 2002; 50:345-57. [PubMed: 12480482]

51. Gibbons M. Science's new social contract with society. Nature. 1999; 402(6761 suppl):C81-4. [PubMed: 10591229]

52. Schroeder SA, Zones JS, Showstack JA. Academic medicine as a public trust. JAMA. 1989; 262:803-12. [PubMed: 2664241] 
Characteristics of Neuromarketing Web Sites $(n=16)$

\begin{tabular}{|c|c|}
\hline \multicolumn{2}{|l|}{ Services offered } \\
\hline fMRI & $31.2 \%(5)$ \\
\hline EEG & $56.3 \%(9)$ \\
\hline Other technologies & $75 \%(12)$ \\
\hline \multicolumn{2}{|l|}{ Business considerations } \\
\hline Costs listed & $6.2 \%(1)$ \\
\hline Clients listed & $25 \%(4)$ \\
\hline \multicolumn{2}{|l|}{ Descriptions of science } \\
\hline Methodology described & $81.2 \%(13)$ \\
\hline Peer reviewed publications on Web site & $31.2 \%(5)$ \\
\hline Peer reviewed publications by lab or affiliates on Web site & $25 \%(4)$ \\
\hline \multicolumn{2}{|l|}{ Professionals on staff } \\
\hline Academicians on staff & $31.2 \%(5)$ \\
\hline MDs listed on staff & $31.2 \%(5)$ \\
\hline PhDs listed on staff & $56.3 \%(9)$ \\
\hline Listing of university affiliation & $6.2 \%(1)$ \\
\hline Any holder of advanced science degree & $56.3 \%(9)$ \\
\hline \multicolumn{2}{|l|}{ Web site format } \\
\hline Picture of brain on home page & $43.8 \%(7)$ \\
\hline Picture of brain function (e.g., fMRI, EEG) on home page & $31.2 \%(5)$ \\
\hline Cartoon graph on home page & $12.5 \%(2)$ \\
\hline Any other graph/visual data on home page & $18.8 \%(3)$ \\
\hline At least one of above graphics & $56.3 \%(9)$ \\
\hline Links of media coverage & $56.3 \%(9)$ \\
\hline \multicolumn{2}{|l|}{ Specific claims } \\
\hline Use of terms truth / real / really & $62.5 \%(10)$ \\
\hline Revealing secrets/subconscious & $62.5 \%(10)$ \\
\hline Predicting future behavior & $6.2 \%(1)$ \\
\hline \multicolumn{2}{|l|}{ Claims of neuromarketing as improvement over other techs } \\
\hline Mitigating factors & $50 \%(8)$ \\
\hline Provide citations for claims & $6.2 \%(1)$ \\
\hline Caveats to technology & $37.5 \%(6)$ \\
\hline \multicolumn{2}{|l|}{ Ethics } \\
\hline Specific ethics section on Web site & $12.5 \%(2)$ \\
\hline Mention of word "ethics" & $12.5 \%(2)$ \\
\hline Advertise for subjects & $12.5 \%(2)$ \\
\hline Risk/benefits description for subjects & $0^{\dagger}$ \\
\hline
\end{tabular}

${ }^{\dagger}$ One includes a link to a Web site in German. 


\section{Examples of Reductive Claims}

Web site Quotation
1 "we use the fMRI ... to learn why consumers make the decisions they do, and that part of the brain is telling them to do it"
2 "instantaneously monitors and records how consumers' brains process what they see, hear, and read from one moment to the next"
3 "the member is exposed to a series of visual and sonic stimuli aimed to stimulate ... a brainwave response to a definite recognition
of the stimulus shown"
"Neuromarketing is now able to identify the type and levels of emotions experienced when consumers are exposed to all types of
commercial messages. It is possible to discover how that information is being processed ... by their brains, the type and degree of
interest shown and the extent to which new information is being established in long term memory."
"The brainwave responses to these stimuli are measured using a patented headband equipped with EEG sensors. The data is then
analyzed to determine if the relevant information is present in the subject's memory."
"fMRI ... allows researchers to view the human mind in real-time, as emotions and cognitive thoughts are at play. Using fMRI, we
can literally "map" the human mind as it reacts to stimuli with which it is presented."
"EEG capability that measures brainwave cognition and emotion on a moment-by-moment basis."
"When a part of the brain becomes active, the brightness of the images changes. By analysing the images using sophisticated
computer programmes, we can quantify and localise brain activity in areas involved in emotion, attention, memory and decision-
making."

